\title{
Phaeochromocytoma crisis presenting with profound hypoglycaemia and subsequent hypertension
}

\author{
Sarah Frankton ${ }^{1}$, Suhail Baithun², Ehab Husain², Katherine Davis ${ }^{3}$, \\ Ashley B. Grossman ${ }^{1}$ \\ ${ }^{1,3}$ Department of Endocrinology, St Bartholomew's Hospital, ${ }^{2}$ Department of Cellular Pathology, The Royal London \\ Hospital, ${ }^{3}$ Department of Acute Medicine, The Royal London Hospital, London, UK
}

\begin{abstract}
A patient was presented with four days of vomiting, abdominal pain and sweating. At presentation the Capillary Blood Glucose (CBG) was $1.7 \mathrm{mmol} / \mathrm{L}$, the Blood Pressure (BP) was 182/102 $\mathrm{mmHg}$, and the pulse $100 \mathrm{bpm}$. On examination, he was sweaty, pale and cold. The initial differential diagnosis was hypoglycaemia secondary to insulin abuse, hypoadrenalism or insulinoma, the transient hypertension being considered a consequence of sympathetic stimulation. He remained clinically well overnight with a CBG of $10-14 \mathrm{mmol} / \mathrm{L}$ following intravenous glucose. The next morning he complained of nausea and abdominal pain. The BP had risen to 203/127 mmHg when he was later reviewed, having been given $10 \mathrm{mg}$ intramuscular metoclopramide. Shortly afterwards, he developed acute pulmonary oedema and had become hypoglycaemic again; a phaeochromocytoma crisis was suspected. Treatment with $\alpha$-adrenoceptor blockade with intravenous phenoxybenzamine was advised. However, the patient deteriorated and died in the Intensive Care Unit within two hours. Autopsy examination confirmed a phaeochromocytoma in the left adrenal, with haemorrhage within the head of pancreas, but no evidence of a pancreatic tumour.
\end{abstract}

Key words: Hypertension, Hypoglycaemia, Phaeochromocytoma

This is an unusual case of a phaeochromocytoma crisis presenting primarily with hypoglycaemia. The tumour did not stain for insulin and the mechanism of the hypoglycaemia remains unclear, but we suspect that this may have occurred via $\beta$-adrenoceptor-medi-

Address for correspondence:

Sarah Frankton, Consultant Physician in Acute Medicine Endocrinology and Diabetes, The Clock Attic, The Royal London Hospital, Whitechapel Road, London. E1 1BB, Tel.: +207377 7000 ext. 3230, Fax: + 2073777337 , e-mail: sarah.frankton@bartsandthelondon.nhs.uk Received 30-06-08, Revised 20-10-08, Accepted 20-11-08 ated release of insulin from the pancreas.

\section{CASE DESCRIPTION}

\section{History}

A 47-year old man from Eastern Europe was referred to the acute medical team complaining of a 4-day history of vomiting, abdominal pain and profuse sweating. He had been noted by the referring doctor to be hypoglycaemic, with a Capillary Blood Glucose (CBG) of 1.5 and $1.8 \mathrm{mmol} / \mathrm{L}$ on two separate occa- 
sions. His blood pressure was 182/112 mmHg.

On the day of admission he had become increasingly tremulous and sweaty. He worked as a personal trainer in a local gym and had been very well until the time of presentation. He had no headache or visual symptoms and had experienced no recent change in weight; there was no known history of hypertension or diabetes mellitus and he was taking no prescribed medication. He had no obvious symptoms of neuroglycopaenia.

He vehemently denied abusing insulin, amphetamines or growth hormone, although he did admit to having abused anabolic steroids 15 years previously and to smoking marijuana occasionally. A friend later informed us that he also took tablets known as "fat burners", which were purchased legally and believed to contain large amounts of caffeine.

His father and a sister were well and living in the Former Yugoslav Republic of Macedonia. There was no family history of note. He smoked 10 cigarettes per day and had previously smoked more heavily but denied any alcohol consumption. There was nothing to note on systemic enquiry.

\section{Examination}

He looked extremely unwell on presentation: he was pale and sweating profusely, peripherally cyanosed and shivering. He was muscular with a Body Mass Index (BMI) of 27.5. He had no increased skin or buccal mucosa pigmentation. His pulse was 100 beats per minute and regular with a blood pressure of $182 / 102 \mathrm{mmHg}$ on initial presentation falling to $115 / 90 \mathrm{mmHg}$ after 30 minutes, both levels being recumbent as he was too ill to be examined standing. There were no signs of heart failure; examination of the respiratory system and abdomen was normal apart from an appendicectomy scar. His visual fields were normal to confrontation; tone, power, coordination and reflexes were all normal and symmetrical. His glucose level was $1.8 \mathrm{mmol} / \mathrm{L}$, fasting, with a $\mathrm{BP}$ of $115 / 90 \mathrm{mmHg}$.

At this stage the differential was between exogenous insulin abuse, an insulin-secreting endocrine tumour or hypoadrenalism.

\section{Management and Clinical Course}

$50 \mathrm{mls} 50 \%$ glucose was administered intravenously followed by an intravenous infusion of $5 \%$ glucose; $100 \mathrm{mg}$ hydrocortisone was given intramuscularly whilst awaiting serum cortisol levels. The results of the initial investigations are given below. The patient initially made a good response and appeared well, his sweating resolved and blood pressure remained around $115 / 60 \mathrm{mmHg}$ overnight with a CBG of 14.2 $\mathrm{mmol} / \mathrm{L}$. However, the following morning the patient again became sweaty and nauseated, with a blood pressure of 202/127 mmHg and he complained of colicky abdominal pain; $10 \mathrm{mg}$ intramuscular metoclopramide was administered. Further blood pressure measurements revealed that he was persistently extremely hypertensive, and the CBG had now fallen to 1.7 $\mathrm{mmol} / \mathrm{L}$. The possibility of a phaeochromocytoma was raised, although the hypoglycaemia remained puzzling. Over the next four hours he deteriorated and developed frank pulmonary oedema; $80 \mathrm{mg}$ intravenous furosemide was given and an intravenous glyceryl trinitrate infusion commenced. The patient was moved to the Intensive Care Unit with a presumed phaeochromocytoma crisis. On arrival he had become profoundly hypotensive and underwent a cardiac arrest before intravenous $\alpha$-adrenoreceptor blockade with phenoxybenzamine could be commenced. Attempts to resuscitate him were unsuccessful. A hospital autopsy examination was carried out three days later.

\section{Results of investigations (Table 1)}

Prior to the instigation of any treatment, plasma glucose was confirmed at $1.8 \mathrm{mmol} / \mathrm{L}$, with inappropriately raised insulin and C-peptide levels of 25.9 $\mathrm{mIU} / \mathrm{L}$ and $1174 \mathrm{pmol} / \mathrm{L}$, respectively (reference range in the presence of hypoglycaemia are $<3 \mathrm{mIU} / \mathrm{ml}$ and $200 \mathrm{pmol} / \mathrm{L}$, respectively). At presentation, the alcohol level was less than $10 \mathrm{mg} / \mathrm{dL}$ and lactate 1.7 $\mathrm{mmol} / \mathrm{L}$ (reference range, $0.5-2.2$ ). Serum cortisol was $1202 \mathrm{nmol} / \mathrm{L}$, excluding adrenal insufficiency, with normal levels of thyroid function tests, prolactin and IGF-1 (99ng/mL; normal median 154).

Following his dramatic clinical deterioration, the serum creatinine rose from $103 \mu \mathrm{mol} / \mathrm{L}$ at presentation to $262 \mu \mathrm{mol} / \mathrm{L}$, blood urea rose from 8.3 to 13.6 $\mathrm{mmol} / \mathrm{L}$, amylase from $244 \mathrm{mmol} / \mathrm{L}$ to $722 \mathrm{mmol} / \mathrm{L}$, ALT 16 to 830U/L, while creatine kinase rose from $117 \mathrm{U} / \mathrm{L}$ to $722 \mathrm{U} / \mathrm{L}$. Troponin T had risen to $3.4 \mathrm{mcg} / \mathrm{L}$. Toxicological analysis for amphetamines was negative but revealed the presence of tetrahydrocannabinoids, 
Table 1. Blood and urine test results from the day of admission to the day of death. Post mortem 19.7.06: Urine Noradrenaline (nmol/L) 278, Urine Adrenaline (nmol/L) <90, Urine Dopamine (nmol/L) 394.

Blood test results (Reference Range, Units)

Date and Time of Sample 12.7.06, 18:16 h (admission) $\quad$ 13.7.06, 15:04 h

Haemoglobin (13.5-15.5 g/dL)

White Cell Count (4.0-11.0 x 10*9/L)

Platelets $\left(150400 \times 10^{*}\right.$ / $\left./ \mathrm{L}\right)$

Sodium (136-146 mmol/L)

Potassium (3.5-5.1 mmol/L)

Chloride (98-106 mmol/L)

Bicarbonate $(22-29 \mathrm{mmol} / \mathrm{L})$

Urea (2.5-6.4 mmo/L)

Serum Creatinine $(62-106 \mu \mathrm{mol} / \mathrm{L})$

Plasma Glucose (mmol/L)

Total Protein $(62-77 \mathrm{~g} / \mathrm{L})$

Albumin (35-50 g/L)

Bilirubin $(1-17 \mu \mathrm{mol} / \mathrm{L})$

Alkaline Phosphatase (40-129 IU/L)

Alanine Aminotransferase (0-40 IU/L)

Aspartate Aminotransferase (12-39 IU/L)

Corrected Calcium (2.15-2.65 mmol/L)

Phosphate $(0.8-1.5 \mathrm{mmol} / \mathrm{L})$

Amylase (<90 IU/L)

C-Reactive Protein $(<10)$

Creatine Kinase (<195 IU/L)

Magnesium (0.7-1.0 mmol/L)

Alcohol (mg/dL)

Serum IgG (5.5-16.5 g/L)

Serum IgA (0.8-4.0 g/L)

Serum IgM (0.4-2.0 g/L)

Serum Electrophoresis

Plasma Lactate $(0.5-2.2 \mathrm{mmol} / \mathrm{L})$

TSH (0.3-4.0 mIU/L)

Free T4 (11-25 pmol/L)

Cortisol (09.00:200-600 nmol/L, asleep <20 nmol/L)

Prolactin $(<496 \mathrm{mIU} / \mathrm{L})$

IGF-1 (94-252 ng/mL, Median 154)

Serum C Peptide (pmol/L)

Insulin (4-20 mIU/L)

Troponin T (up to $0.01 \mu \mathrm{g} / \mathrm{L}$ )

\begin{tabular}{|c|c|}
\hline 16.7 & 18.9 \\
\hline 8.7 & 26.9 \\
\hline 390 & 223 \\
\hline 141 & 143 \\
\hline 3.5 & 4.4 \\
\hline 96 & 100 \\
\hline 29 & \\
\hline 8.8 & 12.6 \\
\hline 103 & 230 \\
\hline 1.8 & 2.6 \\
\hline 88 & 73 \\
\hline 56 & 46 \\
\hline 11 & 23 \\
\hline 125 & 150 \\
\hline 16 & 419 \\
\hline 18 & 233 \\
\hline 2.38 & 2.05 \\
\hline 1.42 & 2.42 \\
\hline 224 & 830 \\
\hline$<5$ & 6 \\
\hline 117 & 722 \\
\hline 1.08 & 1.02 \\
\hline$<10$ & \\
\hline 7.8 & \\
\hline 2.79 & \\
\hline 0.92 & \\
\hline
\end{tabular}

Normal Pattern

1.7

$0.21 \quad 0.25$

$19.8 \quad 20.5$

$1202>1749$

107

99

1174

25.9

3.4 
metabolites of marijuana.

An echocardiogram in the Intensive Care Unit showed the left ventricular systolic function was severely reduced with an ejection fraction of $15 \%$ $20 \%$ and plain chest radiology confirmed pulmonary oedema.

\section{Post-mortem examination (Figures 1-3)}

A post-mortem examination confirmed the presence of a phaeochromocytoma in the left adrenal: the tumour measured $6.5 \times 6.5 \mathrm{~cm}$ with central haemorrhage. The phaeochromocytoma stained with chromogranin and synaptophysin, with positivity of S100

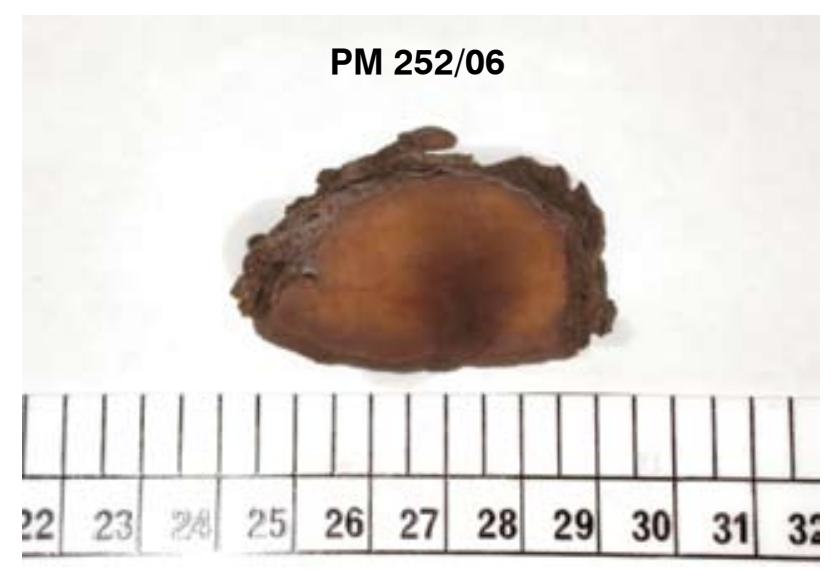

Figure 1. Macroscopic sample demonstrating cut surface of the adrenal tumour showing a pale brown cut with central haemorrhage.

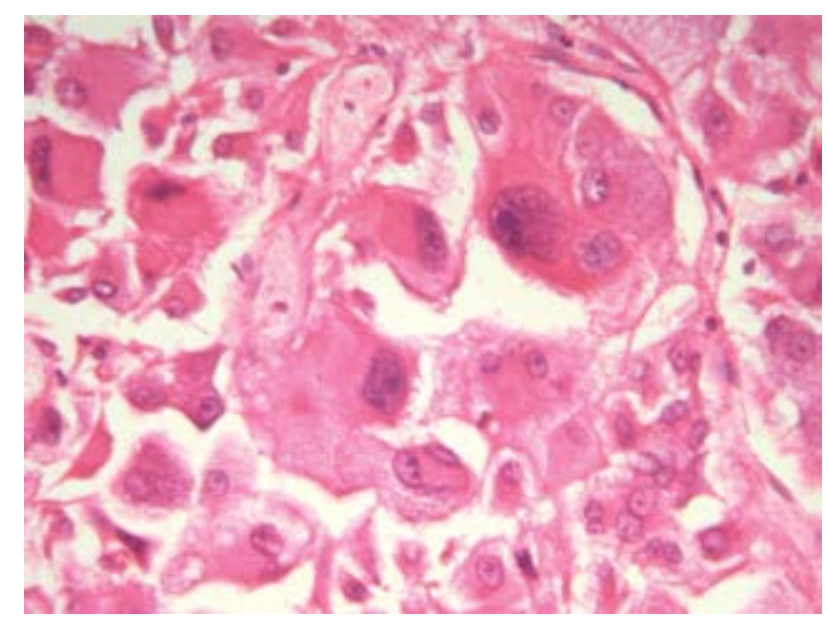

Figure 2. Microscopic sample of the phaeochromocytoma. Diffuse sheets of large epithelioid cells with large pleomorphic nuclei and prominent nucleoli.

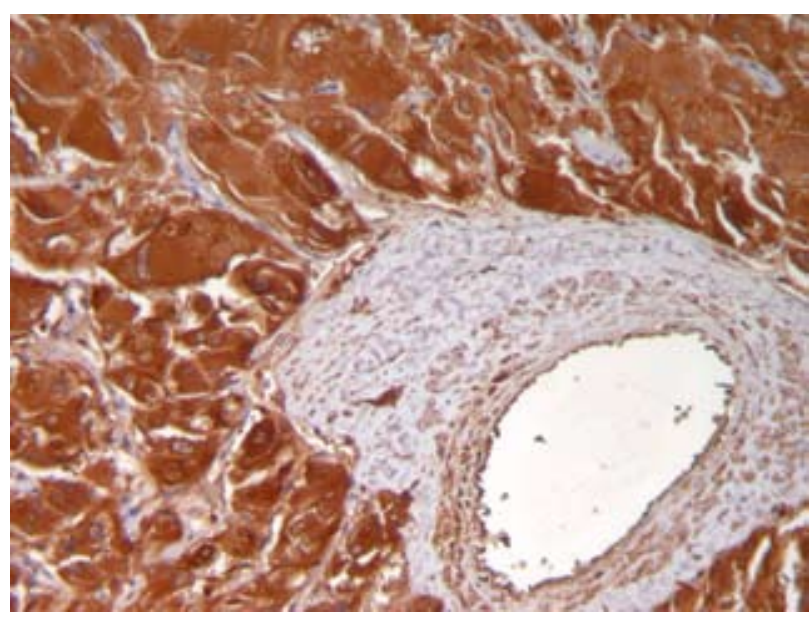

Figure 3. Microscopic sample: Diffuse cytoplasmic chromogranin positivity in the tumour cells is seen.

for sustentacular cells. However, the tumour was immunohistochemically negative for insulin. The head of pancreas also showed haemorrhage, but there was no evidence of a pancreatic tumour throughout the pancreas. Histological examination of the heart revealed patchy oedematous changes.

\section{DISCUSSION}

This is an unusual case of a phaeochromocytoma crisis presenting with hypoglycaemia and only later with hypertension. The tumour did not stain for insulin and the mechanism of the hypoglycaemia remains unclear. There was no islet cell tumour anywhere in the pancreas, the high levels of C-peptide suggest that there was no exogenous insulin administered, and testing for insulin secretagogues was negative. This implies that the high and inappropriate levels of insulin were a direct eutopic islet cell response to the phaeochromoctyoma.

Phaeochromocytoma is classically associated with hyperglycaemia. Excess catecholamine secretion by such tumours inhibit the release of insulin from the pancreas by $\alpha$-adrenoceptor stimulation., ${ }^{1,2}$ However, in contrast, stimulation of the $\beta$-adrenoceptors results in increased release of insulin from the pancreatic cells. ${ }^{1}$ One hypothesis is that in this patient the profound hypoglycaemia witnessed resulted from a dominant $\beta$-adrenoceptor mediated release of insulin from the pancreas, overriding the $\alpha$-adrenoceptor mediated 
inhibition of insulin release and hence inappropriately high insulin levels for the prevailing plasma glucose levels. ${ }^{3,4}$ The patient took regular strenuous exercise and had also been vomiting for the four days prior to presentation: his hepatic and skeletal muscle glycogen stores were thus likely to have been depleted, which may have exacerbated the insulin effect. In general, the regulation of insulin is under dominant inhibitory $\alpha$-adrenoceptor control, principally via the $\alpha 2$-adrenoceptor, with an increase in glucose tolerance on treatment of the phaeochromocytoma. ${ }^{5}$ However, as noted above, glycogen stores may have been depleted, and it is conceivable that if adrenaline rather than noradrenaline release was favoured, then $\beta$-adrenoceptor-mediated effects may have become dominant, even though $\beta_{2}$-adrenoceptors can be shown to increase insulin resistance in vitro. ${ }^{6}$

Another possible mechanism for the inappropriately high insulin levels in this patient include direct release from damaged pancreatic tissue given the large area of haemorrhage found at the time of post-mortem examination. There also are several case reports of severe hypoglycaemia occurring postoperatively in patients undergoing adrenalectomy for phaeochromocytoma, and it is possible that infarction of such a tumour may have the same effect. ${ }^{7}$ However, there was only a small area of central haemorrhage in this tumour post-mortem, making this an unlikely contributory factor.

There have been very few case reports of patients with a phaeochromocytoma presenting with hypoglycaemia. Uysel and colleagues described the case of a patient presenting with an insulin-secreting paraganglioma, while Innerman and colleagues reported a patient presenting with hypoglycaemia and a phaeochromocytoma metastatic to the liver. ${ }^{8,9}$ The mechanism of hypoglycaemia is clear in the former case, while in the latter several explanations proposed by the authors included secretion of insulin or a substance with insulin-like activity by the tumour, decreased gluconeogenesis, disruption of glucagon metabolism, increased utilisation of glucose by the tumour and/or a local effect of the tumour on the hepatic parenchyma. Finally, the phaeochromocytoma in our patient was large, increasing the chance of malignancy, a diagnosis which can rarely be made on histopathological features. In such cases, tumoural hypoglycaemia can be secondary to the ectopic secretion of factors related to IGF-II; this is extremely unlikely in this instance as one would then expect C-peptide levels to be suppressed.

We believe that his case demonstrates the importance of recognising that a phaeochromocytoma crisis can be associated with hypoglycaemia as well as the more frequently described hyperglycaemia, and possible mechanisms for this phenomenon have been discussed. Our patient showed only intermittent hypertension, which could be attributed to previous caffeine and marijuana use, or to sympatho-adrenal activations caused by hypoglycaemia. Previous data have shown correlations between the size of a tumour, the rate of turnover of catecholamines within the tumour and the pattern of catecholamine metabolites in the urine..$^{10}$ It has been suggested that in some phaeochromocytomas much of the catecholamine synthesised is degraded directly in the tumour before it ever reaches the circulation. This process may partially "protect" the patient from the cardiovascular effects of his tumour and thereby modify the clinical course of the disease. ${ }^{10}$ Indeed, this theory may account for the later presentation of the cardiovascular effects seen in our patient and the normal levels of urinary catecholamines found.

The case also serves to remind clinicians that metoclopramide can cause the release of catecholamines in patients with phaeochromocytomas, although the preceding acute administration of hydrocortisone may also be a salient factor. ${ }^{11}$ Leow and Loh reported three patients with phaeochromocytomas who developed acute crises after being given metoclopramide. ${ }^{12}$ Stimulation of the dopamine type 2 receptors on presynaptic nerve endings inhibits the release of catecholamines and ganglion transmission, while metoclopramide accentuates noradrenaline release via presynaptic type 2-dopamine receptor blockade; it may also have a direct effect on catecholamines release from phaeochromocytomas. ${ }^{13,14}$ It may thus act as a potent trigger of a hypertensive crisis in the presence of a phaeochromocytoma. In summary, in the light of this case, phaeochromocytoma may be considered a rare but important cause of hypoglycaemia. 


\section{REFERENCES}

1. Porte D Jr, 1967 A receptor mechanism for the inhibition of insulin release by epinephrine in man. J Clin Invest 46: 86-94.

2. Cerasi E, Effendic S, Luft R, 1969 Role of adrenergic receptors in glucose-induced insulin secretion in man. Lancet 9: 301-302.

3. Ullrich S, Wollheim CB, 1985 Expression of both alpha 1- and alpha 2-adrenoceptors in an insulin-secreting cell line. Parallel studies of cytosolic free $\mathrm{Ca} 2+$ and insulin release. Mol Pharm 28: 100-106.

4. Nonogaki K, 2000 New insights into sympathetic regulation of glucose and fat metabolism. Diabetologia 43: 533-549.

5. Diamanti-Kandarakis E, Zapanti E, Peridis M-H, Ntavos P, Mastorakos G, 2003 Insulin resistance in pheochromocytoma improves more by surgical rather than by medical treatment. Hormones(Athens) 2: 61-66.

6. Doronin S, Wang Hy HY, Malbon CC, 2002 Insulin stimulates phosphorylation of the beta 2-adrenergic receptor by the insulin receptor, creating a potent feedback inhibitor of its tyrosine kinase. J Biol Chem 277: 10698-10703.

7. Jude EB, Sridhar CB, 2000 Prolonged hypoglycaemia following surgical removal of phaeochromocytoma.
Postgrad Med J 76: 39-40.

8. Uysal M, Temiz S, Gul M Yarman S, Tanakol R, Kapran Y, 2007 Hypoglycaemia due to ectopic release of insulin from a paraganglioma. Horm Res 67: 292-295

9. Innerman SC, Sener SF, Khandehar JD, 1982 Causes and evaluation of tumour-induced hypoglycaemia. Arch Surg 117: 905-908.

10. Crout JR and Sjoerdsma A, 1964 Turnover and metabolism of catecholamines in patients with pheochromocytoma. J Clin Investig: 43: 94-102.

11. Rosas AL, Kasperlik-Zaluska AA, Papierska L, Bass BL, Pacak K, Eisenhofer G, 2008 Pheochromocytoma crisis induced by glucocorticoids: a report of four cases and review of the literature. European $\mathbf{J}$ of Endocrinol 158: 423-429.

12. Leow MK, Loh KC, 2005 Accidental provocation of phaeochromocytoma: the forgotten hazard of metoclopramide? Singapore Med J 46: 557-560.

13. Kuchel O, Buu NT, Hamet P, Larochelle P, 1985 Effect of metoclopramide on plasma catecholamine release in essential hypertension. Clin Pharmacol Ther 37: $372-$ 375 .

14. Agabiti-Rosei E, 1995 Hypertensive crises in patients with phaeochromocytoma given metoclopramide. Annals Pharmacol 29: 381-383. 